\title{
Rechallenge chemotherapy as a third line treatment option for metastatic colorectal carcinoma
}

\section{Metastatik kolorektal kanser hastalarında 3. basamak tedavi seçeneği: rechallenge kemoterapi}

Ersin Özaslan, Oktay Bozkurt, Ayşe Ocak Duran, Mahmut Uçar, Mevlude İnanç, Metin Özkan

Department of Medical Oncology, Erciyes University Faculty of Medicine, Kayseri, Turkey

Geliş Tarihi: 02.03.2017

Kabul Tarihi: 20.04.2017

Doi: 10.21601/ortadogutipdergisi.296006

\begin{abstract}
Aim: Currently, there is required effective option in third line therapy after irinotecan and oxaliplatin based regimen because of survival of metastatic colorectal carcinoma (mCRC) increase. A repeated chemotherapy regimen (rechallenge therapy) may be an option in selective patients.

Material and Method: Patients were rechallenged with irinotecan or oxaliplatin regimen as a third line therapy which was the same therapy that they received as the first line. Response Evaluation Criteria in Solid Tumors (RECIST) was used to retrospectively calculate tumor response and Kaplan Meier method to calculate survival.
\end{abstract}

Results: Forty-five patients were found to be eligible for this study. The median follow up duration was 29 months. Thirty-three patients (73\%) had been lost during follow up. Of the rechallenge treatments, $23(51 \%)$ patients were administered irinotecan and $22(49 \%)$ oxaliplatin based regimens. Most patients had a good performans status as 0 or 1 and K-RAS wild-type was detected in $31(69 \%)$ of the patients. The common toxicities were haematologic and gastrointestinal, mostly grade 1 and 2 . Response rate was $8.9 \%$, while $25(55.5 \%)$ of the patients had stable disease. Clinical benefit rate was calculated as $64.4 \%$. The median progression-free survival (PFS) as 6 months (95\% CI: 4.68-9.55 months) and the median overall survival (OS) was found as 10 months (95\% CI: 7.00-12.99 months).

Conclusions: The results of this study indicate that rechallenge treatment may be a right choice as a third line therapy for selected patients.

Keywords: metastatic colorectal carcinoma, rechallenge chemotherapy, third line, salvage, reintroduction 


\section{Öz}

Amaç: Metastatik kolorektal kanser (mKRK) hastalarında hedefe yönelik ajanlarla birlikte sağkalım gittikçe uzamaktadır. Bu nedenle irinotekan ve oxaliplatin bazlı tedavi sonrası 3. basamakta etkili bir tedaviye ihtiyaç vardır. Aynı kemoterapi rejiminin tekrarı (rechallenge kemoterapi) seçilmiş hastalarda tedavi seçeneği olabilir. Biz de mKRK hastalarında rechallenge kemoterapi etkinliğini ve yan etkilerini belirtecek bir çalışma yapmayı amaçladık.

Gereç ve Yöntem: İlk basamakta verilen irinotekan ve oxaliplatin bazlı tedavi rejimini 3. basamakta yeniden hastalara uygulandı. Tümör cevabını değerlendirmede RECIST kriterleri, sağkalım analizi için ise Kaplan-Meier metodu kullanıldı.

Bulgular: Çalışma kriterlerine uygun 45 hasta bu retrospektif çalışmaya alındı. Ortanca takip süresi 29 ay idi. 33 hasta takipte ex oldu. Hastaların 23'ü irinotekan bazlı, 22'si oxaliplatin bazlı tedavi aldı. Hastaların çoğunluğunun (\%93) performans skoru 0 ve 1 idi. K-RAS mutasyonu negatif olan hasta sayısı 31 (\%69) idi. Başlıca toksisiteler hematolojik ve gastrointestinal sisteme ait idi ve çoğunluğu grad 1 ve 2 idi. Objektif cevap oranı \%8,9, stabil cevap oranı ise \%55,5 idi. Ortanca progresyonsuz sağkalım süresi 6 ay (95\% CI: 4,68-9,55 ay), ortanca genel sağkalım süresi ise 10 ay (95\% CI: 7,00-12,99 ay) olarak bulundu.

Sonuç: mKRK'li seçilmiş hastalarda rechallenge kemoterapi 3.basamakta uygun bir tedavi seçeneği olabilir.

Anahtar Kelimeler: Metastatik kolorektal karsinom, rechallenge kemoterapi, 3. sira, salvaj tedavi, reintrodüksiyon

\section{Introduction}

Irinotecan or oxaliplatin combined with 5-fluorouracil (5-FU) and leucovorin (LV) is recognized as the standard chemotherapy regimen in the treatment of metastatic colorectal cancer (mCRC) [1]. It has been demonstrated that the combination of chemotherapy with targeted therapy including antiepidermal growth factor receptor (anti EGFR) and antivascular endothelial growth factor (anti VEGF) increases the rate of survival [2-4].

There is a lack of data about the beneficial effects of systemic therapy after the progression of first two lines of palliative combination chemotherapy in mCRC patients. Treatment options as third and further lines are reserved for patients who show progression of disease after receiving cytotoxic chemotherapy combined with targeted treatments. Regorafenib can be regarded as an option for third and further line therapy in patients with disease resistant to chemotherapy, but it should only be considered for patients who are in good physical condition [5]. Cytotoxic chemotherapeutic agents such as capecitabine, uraciltegafur (UFT), mitomycin C, raltitrexed and gemcitabine have limited or no effect. Rechallenge therapy is defined as repeating the same treatment to which the tumor has already proved to be resistant, for a second or subsequent time following an intervening treatment. Oxaliplatin or irinotecan based retreatment regimens might be a significant option in eligible patients. However, it has been concluded in only a few studies that rechallenge treatment might be useful in eligible mCRC patients with mCRC [6]. In this study, we evaluated the effectiveness of rechallenge therapy in mCRC patients using a combination of 5-FU and oxaliplatin or irinotecan with or without EGFR or VEGF inhibitors as a third line therapy.

\section{Material and Method}

Data were obtained from the oncology department in the xxx University, Faculty of Medicine, retrospectively. Patients who had received oxaliplatin or irinotecan regimens and had a positive response at first evaluation in first line therapy were considered eligible for the study. Forty-five patients who had a diagnosis of mCRC from October 2006 to August 2014 and received oxaliplatin or irinotecan combined with fluoropyrimidine \pm bevacizumab as the first line therapy were enrolled. These patients were then administered rechallenge therapy with oxaliplatin or combined with fluoropyrimidine \pm bevacizumab or cetuximab as the third line treatment. Tumor markers, imaging methods and clinical evaluations were employed in order to monitor progression of disease. Evaluation of 
response was carried out in accordance with the Response Evaluation Criteria in Solid Tumors criteria (RECIST) every 2-3 months. The reason for changing regimens was disease progression in all patients. And also, we have included patients whose disease was progression with rechallenge therapy. Toxicity was assessed according to the common toxicity criteria of the National Cancer Institute (NCI), while in cases of adverse effects the doses were reduced or delayed, if necessary. Dose of chemotherapy was reduced by $20 \%$ in case of grade $3 / 4$ side effects.

SPSS 18.0 software (IBM, USA) was used for statistical analyses. Progression free survival (PFS) was calculated as the duration between initiation of repeat therapy and radiologic progression or death. Survival was determined using the Kaplan-Meier method.

\section{Results}

\section{Patients Characteristics}

A total of 45 patients were included in the study. Twenty-nine (64.4\%) patients were male and 16 (35.6\%) patients were female. The median age was 58 years (range, 33-78 years). The median follow up was found as 29 months (range, 14-68 months). Thirty-three (73.3\%) patients died during follow up. Looking at the first line regimens, $23(51.1 \%)$ of the patients were administered irinotecan and 22 (48.9\%) received oxaliplatin combined regimens. In 38 patients, bevacizumab and in one patient cetuximab were added to chemotherapy during first line therapy. Six patient did not receive targeted therapy in first line. Oxaliplatin or irinotecan based regimens were substituted during second line therapy.

Among patients receiving rechallenge treatments, 23 received FOLFIRI, 14 FOLFOX6 and 8 XELOX regimens. Bevacizumab was used in 22 patients and cetuximab was used in 17 patients patient with rechallenge chemotherapy. Eastern Cooperative Oncology Group (ECOG) performans status (PS) was mostly (93\%) determined as 0 or 1 in all patients included. Fourteen patients had PS of 0,28 patients PS of 1 and 3 patients PS of 2. K-RAS wild type was detected in $31(68.8 \%)$ of the all patients. The majority of the baseline characteristics (age, sex, K-RAS status, presence of surgery, primary tumor site, ECOG PS score and number of metastases) were similar among patients with receiving oxaliplatin and irinotecan based therapy $(p>0.05)$. Only the number of metastases was close to statistical significance $(\mathrm{p}=0.08)$. Twenty patients had single metastases and 11 had multipl metastases in patients with receiving irinotecan based therapy whereas 6 patients had single metastases and 16 had multipl metastases in patients with receiving oxaliplatin based therapy.

\section{Safety}

Some toxicities were observed in twenty-nine patients (64.4\%), usually as grades 1 and 2 during third line therapy. The most common complications included gastrointestinal and hematologic toxicities. On the other hand, the most common grade $3 / 4$ toxicities were found as neutropenia in twenty patients, fatique in seven patients, diarrhea in four patients, nausea-vomiting in two patients, mucositis in two patients, thrombocytopenia in two patients, skin eruption in two patients and thromboembolism in one patients. Grade $3 / 4$ neuropathy did not occur due to oxaliplatin. The grade $3 / 4$ toxicity rate was $43 \%$ and $31 \%$ in irinotecan and oxaliplatin based therapies, respectively. These toxicities did not lead to the cessation of treatment in any of the patients. Dose adjustment was adequate for these patients. No patients died due to toxicities resulting from chemotherapy. The adverse effects due to treatment are given in Table 1. In general, both regimens were well tolerated.

\begin{tabular}{|l|c|c|c|c|}
\hline \multicolumn{7}{|l|}{ Table 1. Adverse effects of third line therapy } \\
\hline Toxicity & Grade 1 & Grade 2 & Grade 3 & Grade 4 \\
\hline Neutropenia & 2 & 5 & 5 & 7 \\
\hline Anaemia & 2 & 3 & - & - \\
\hline Thrombocytopenia & 2 & 3 & 1 & 1 \\
\hline Fatigue & 6 & 4 & 4 & 3 \\
\hline Diarrhoea & 4 & 2 & 3 & 2 \\
\hline Nausea-vomiting & 2 & - & 2 & - \\
\hline Mucositis & 2 & 4 & 1 & 1 \\
\hline Neuropathy & 6 & 8 & - & - \\
\hline Hypertension & 2 & 5 & - & - \\
\hline Proteinuria & - & 4 & - & - \\
\hline Skin eruption & 3 & 5 & 1 & 1 \\
\hline
\end{tabular}

\section{Efficacy}

Overall, the median PFS value was calculated as 6.0 months (95\% CI: 4.68-7.31 months). The median PFS was found as 5.0 months (95\% CI: $2.74-7.26)$ for the oxaliplatin based 
regimen and 8.0 months ( $95 \% \mathrm{CI}: 6.44-9.55$ months) for the irinotecan based regimen (p:0.002) (Fig. 1A). Whereas the median overall survival (OS) was calculated as 10.0 months (95\% CI: 7.00-12.99 months), this value was calculated as 9.0 months for oxaliplatin (95\% CI: 7.57-10.42) and 16.0 months (95\% CI: 8.35-23.64 months) for irinotecan based regimens $(\mathrm{p}=0.025)($ Fig $1 \mathrm{~B})$.

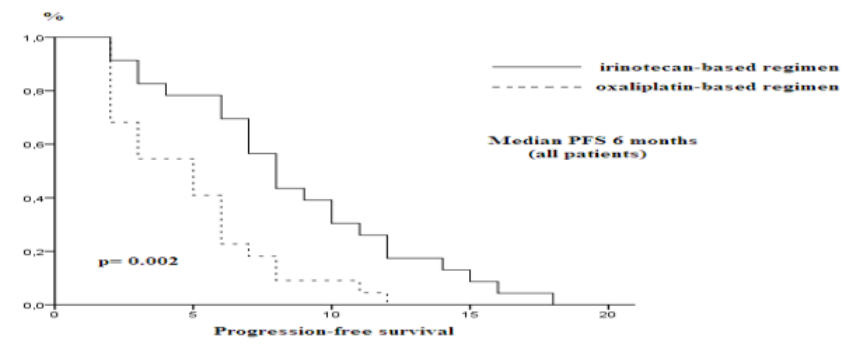

Figure 1a. Kaplan-Meier curves for progression free survival (PFS) according to rechallenge therapy with irinotecan and oxaliplatin based regimen.

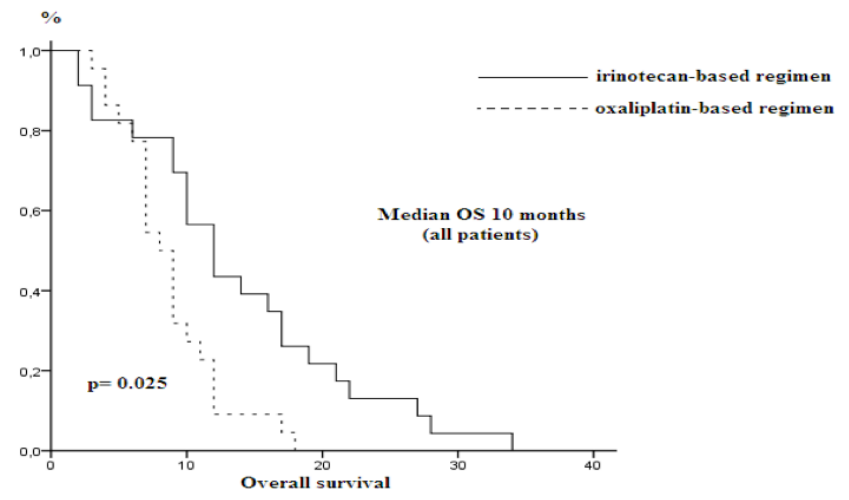

Figure 1b. Kaplan-Meier curves for Overall Survival (OS) according to rechallenge therapy with irinotecan and oxaliplatin based regimen.

When targeted therapy was considered, the median PFS was found as 7.0 and 6.0 months $(\mathrm{p}=0.41)$ and the median OS as 12.0 and 10.0 months $(\mathrm{p}=0.88)$ for rechallenge chemotherapy in combination with cetuximab or bevacizumab, respectively. Namely, the choice of targeted therapy regimen in combination with rechallenge therapy or the choice of rechallenge therapy regimens (irinotecan or oxaliplatin based) was insignificant for survival according to our study. PFS and OS were shorter without targeted therapy (5.0 months and 7.0 months respectively, $\mathrm{p}=0.532$ and $\mathrm{p}=0.426$ respectively).
Overall, the clinical benefit rate was found as $64.4 \%$ and the response rate (RR) as $8.9 \%$. Complete response (CR) was observed in 1 patient $(2.2 \%)$, partial response (PR) in 3 patients $(6.7 \%)$ and stable disease (SD) in 25 patients (55.5\%). Considering therapy regimens, the tumor clinical benefit rate was found as $54.5 \%$ for oxaliplatin and $73.9 \%$ for irinotecan based regimens $(\mathrm{p}=0.175)$ (Table 2$)$.

Table 2. Response rates (RR) for rechallenge treatment regimens

\begin{tabular}{|c|c|c|c|c|c|c|}
\hline & $\mathrm{CR}$ & PR & SD & PD & $\begin{array}{l}\mathrm{RR} \\
(\%)\end{array}$ & $\mathrm{p}$ \\
\hline $\begin{array}{l}\text { All patients } \\
\text { (n: 29) }\end{array}$ & $\begin{array}{l}1 \\
(3.4 \%)\end{array}$ & $\begin{array}{l}3 \\
(10.4 \%)\end{array}$ & $\begin{array}{l}15 \\
(51.7 \%)\end{array}$ & $\begin{array}{l}10 \\
(34.5 \%)\end{array}$ & 8.9 & \\
\hline $\begin{array}{l}\text { Irinotecan-based } \\
\text { Regimen (n: 19) }\end{array}$ & $\begin{array}{l}1 \\
(5.2 \%)\end{array}$ & $\begin{array}{l}3 \\
(15.8 \%)\end{array}$ & $\begin{array}{l}9 \\
(47.3 \%)\end{array}$ & $6(31.7)$ & 17.3 & \multirow[b]{2}{*}{0.04} \\
\hline $\begin{array}{l}\text { Oxaliplatin- } \\
\text { based Regimen } \\
\text { (n: 10) }\end{array}$ & 0 & 0 & $6(60 \%)$ & $4(40 \%)$ & 0 & \\
\hline
\end{tabular}

\section{Discussion}

Phase III studies with best supportive care (BSC) as control in the third line setting showed that the expected median OS was 4-5 months [5,7] and thus the different therapies might be compared with this number. Recently, the addition of targeted therapies such as bevacizumab, panitumumab and cetuximab to oxaliplatin or irinotecan based regimens indicated that overall survival reached up to 41.3 months [8-10]. Due to prolongation of survival, new treatment options are needed after the first two lines. However, there is no accepted treatment except the regorafenib after the first two lines for $\mathrm{mCRC}$ in the literature [5]. When the treatment method is selected taking into account the conventional dogma of primary and secondary resistance, the role of any rechallenge therapy including chemotherapy and biologic therapy, chemotherapy alone or biologic therapy alone remains unclear. Thus, it may not seem reasonable to rechallenge patients disease with a drug/drugs to which the tumor is resistant. However there is little evidence about the benefit of rechallenge therapy for $\mathrm{mCRC}$ [11].

Currently, there are only a few studies with small number of patients in the literature which evaluate rechallenge chemotherapies. In one retrospective study analyzing rechallenge with FOLFOX, 6 of 29 patients (20.7\%) 
achieved an objective response. Fifteen patients (52\%) had SD and only $27 \%$ of cases had progressive disease. PFS was found as 4.2 months and OS as 9.7 months [12]. Another phase II study evaluated the effectiveness of rechallenge with an oxaliplatin based regimen in 18 patients with $\mathrm{mCRC}$ refractory oxaliplatin, irinotecan and 5-FU. Control of the disease was detected in 39\% (n:7) of cases after 12 weeks [13].

In third line therapy, the role of combining anti VEGFR or anti EGFR with rechallenge therapy (FOLFIRI or FOLFOX) is stil not clear [11]. A retrospective analysis was conducted to evaluate the effectiveness of bevacizumab with either FOLFIRI (57\%) or FOLFOX (43\%) as third line therapy in 39 patients who previously received FOLFIRI and FOLFOX. The authors reported median PFS as 5.3 and OS as 9.5 months [14]. Another retrospective analysis evaluated the effectivenes of cetuximab with FOLFIRI, as third- line therapy, and reported a PFS of 15.3 weeks, while OS was not reported in 256 patients of the evaluated 2006 patients [15]. In studies about rechallenge treatment, in combination with cetuximab, the rechallenge chemotherapy regimen was mostly monotherapy. One hundred and sixty three patients, who were administered biweekly cetuximab in combination with irinotecan were evaluated in a phase II trial. The median PFS was reported as 4.3 and $\mathrm{OS}$ as 10.8 months in these patients [16]. In some retrospective studies $[17,18]$, third line rechallenge irinotecan therapy, in combination with cetuximab, was evaluated. In these studies survival was similar (PFS: 5.4/5.4 months and OS: 8.9/10.4 months) (Table 3).

Table 3. Third-line therapy regimens for $\mathrm{mCRC}$ in the literature

\begin{tabular}{|l|c|c|c|c|c|}
\hline Treatment regimens & $\begin{array}{c}\text { Number of } \\
\text { patients }\end{array}$ & $\begin{array}{c}\text { Median PFS } \\
\text { (months) }\end{array}$ & $\begin{array}{c}\text { Median OS } \\
\text { (months) }\end{array}$ & $\begin{array}{c}\text { Response Rate } \\
(\%)\end{array}$ & $\begin{array}{c}\text { Clinical benefit rate } \\
(\%)\end{array}$ \\
\hline Bevacizumab + Folfiri/Folfox (14) (rechallenge therapy) & 39 & 5.3 & 9.5 & 9.5 & 61.9 \\
\hline Cetuximab+Folfiri/irinotecan/others (15) (rechallenge therapy) & 2006 & 3.7 & NR & NR & NR \\
\hline Cetuximab + irinotecan (16,17,18) (rechallenge therapy) & $65-163$ & $4.3-5.4$ & $8.9-10.8$ & $18-25$ & $68-82$ \\
\hline Mitomycin C + UFT (28,30,31,32) & $20-44$ & $2.5-5.0$ & $6.0-7.5$ & $7.3-9.3$ & $26-36$ \\
\hline Mitomycin C + capecitabine (24,26,27) & $21-61$ & $2.0-3.0$ & $6.0-6.8$ & $4.0-8.0$ & $24-48$ \\
\hline Capecitabine (23,25,33) & $20-60$ & $2.8-4.0$ & $5.2-9.7$ & $0-7$ & $15-53$ \\
\hline Mitomycin C + raltitrexed (22,34) & $18-21$ & $2.3-3.0$ & $5.0-6.0$ & $0-5$ & $30-43$ \\
\hline 5-FU + gemcitabine (29) & 37 & 4.2 & 8.9 & 10.8 & 62.2 \\
\hline Regorafenib (5) & 500 & 1.9 & 6.4 & 1 & 42 \\
\hline This study & 29 & 7 & 11 & 13.8 & 65.5 \\
\hline
\end{tabular}

In studies about rechallenge treatments, the survival rates for rechallenging in third or further line therapies were similar to only third line therapy [6]. Sogabe et al. [19] reported on 51 patients who had received third or further line rechallenge therapy with FOLFIRI (68\%) / FOLFOX $(24 \%)$ / FUFA (8\%) plus bevacizumab. The median PFS in that study was reported as 5.6 months, median OS (20 events) as 11.8 months and the response rate as $11.8 \%$. In another study, 46 patients who were given a bevacizumab combination with rechallenge therapy (FOLFIRI 78\%, FOLFOX 20\%, FUFA 2\%) were evaluated. The median PFS was found as 8.9 and median OS as 13.8 months among these patients [20]. In a retrospective study in which 16 patients received FOLFOX in combination with panitumumab in third and further lines, the median PFS was 3.1, OS was 8 months and RR was $12.5 \%$ [21].

Although there is no evidence supporting the use of anti EGFR and anti VEGF in third or further line therapy, these results suggest that rechallenge of cytotoxic chemotherapy with anti VEGF or anti EGFR as salvage treatment may be useful and effective in selected patients. Similarly, PFS and OS were longer with targeted therapy in this study.

In phase II and retrospective studies in the literature, the patients who received prior 5-FU, irinotecan and oxaliplatin had undergone various third line regimens. These regimens were as follows: mitomycin $\mathrm{C}+\mathrm{UFT}$, mitomycin $\mathrm{C}+$ capecitabine, mitomycin $\mathrm{C}+$ raltitrexed, capecitabine 
+ gemcitabine, 5-FU + gemcitabine and capecitabine monotherapy [6] (Table 3). In these studies, the number of patients ranged between 18 and 61. The median PFS ranged between 2 and 5 months and the median OS between 5 and 9.7 months, while RR showed variability in the range of 0 to $10.8 \%$. The longest median PFS was achieved in Michalaki's phase II trial evaluating 44 patients [22]. The longest median OS was achieved in a retrospective study by Lee et al. [23] in which 60 patients were assessed. In a phase III CORRECT study on regorafenib, limited improvement was demonstrated in survival. PFS was only 1.9 months that is very short term [5]. As shown, the effect on survival of these treatment modalities was more shortterm than that of rechallenge treatment.

In our study, survival durations were longer when compared with the literature. The causes of this difference may be the following: 1 . In our study rechallenge chemotherapy regimens were combined with anti VEGFR and anti EGFR agents (87\%) 2. The rate of K-RAS wild type was relatively high among our patients (69\%) 3 . The ECOG PS score was 0 and 1 in almost all of our patients (93\%) 4 . Our patients consisted of those in whom disease who had not progressed with first line therapy for at least 6 months. Therefore it can be suggested that rechallenge therapy could be more effective in selected patients.

In conclusion, the present study and former studies indicate that rechallenge treatment could be more effective than other chemotherapy regimens and regorafenib that accepted form of treatment today in third line, for selected patients in mCRC. At present, with the aid of improved treatment choices survival is gradually increasing in mCRC patients. This means that many patients will require third line therapy. So, rechallenge treatment may be a good option as a third line therapy for selected patients in mCRC.

\section{Declaration of conflicting interests}

The author declared no conflicts of interest with respect to the authorship and/or publication of this article.

\section{References}

1. Fuchs CS, Marshall J, Mitchell E, et al. Randomized, controlled trial of irinotecan plus infusional, bolus, or oral fluoropyrimidines in first-line treatment of metastatic colorectal cancer: results from the BICC-C Study. J Clin Oncol 2007;25:4779-86.
2. Hurwitz H, Fehrenbacher L, Novotny W, et al. Bevacizumab plus irinotecan, fluorouracil, and leucovorin for metastatic colorectal cancer. N Engl J Med 2004;350:2335-42.

3. Van Cutsem E, Kohne $\mathrm{CH}$, Hitre E, et al. Cetuximab and chemotherapy as initial treatment for metastatic colorectal cancer. N Engl J Med 2009;360:1408-17.

4. Peeters M, Price TJ, Cervantes A, et al. Randomized phase III study of panitumumab with fluorouracil, leucovorin, and irinotecan (FOLFIRI) compared with FOLFIRI alone as secondline treatment in patients with metastatic colorectal cancer. J Clin Oncol 2010;28:4706-13.

5. Grothey A, Van Cutsem E, Sobrero A, et al. Regorafenib monotherapy for previously treated metastatic colorectal cancer (CORRECT): an international, multicentre, randomised, placebocontrolled, phase 3 trial. Lancet 2013;381:303-12.

6. Nielsen DL, Palshof JA, Larsen FO, Jensen BV, Pfeiffer P. A systematic review of salvage therapy to patients with metastatic colorectal cancer previously treated with fluorouracil, oxaliplatin and irinotecan +/- targeted therapy. Cancer Treat Rev 2014;40:701-15.

7. Jonker DJ, O'Callaghan CJ, Karapetis CS, et al. Cetuximab for the treatment of colorectal cancer. N Engl J Med 2007;357:2040-8.

8. Schwartzberg LS, Rivera F, Karthaus M, et al. PEAK: a randomized, multicenter phase II study panitumumab plus modified fluorouracil, leucovorin and oxaliplatin (mFOLFOX6) or bevacizumab plus mFOLFOX6 in patients with previously untreated, unresectable, wildtype KRAS exon 2 metastatic colorectal cancer. J Clin Oncol 2014;32:2240-7.

9. Douillard JY, Siena S, Cassidy J, et al. Final results from PRIME: randomized phase III study of panitumumab with FOLFOX4 for first-line treatment of metastatic colorectal cancer. Ann Oncol 2014;25:1346-55.

10. Heinemann V, von Weikersthal LF, Decker T, et al. FOLFIRI plus cetuximab versus FOLFIRI plus bevacizumab as firstline treatment for patients with metastatic colorectal cancer (FIRE-3): a randomised, open-label, phase 3 trial. Lancet Oncol 2014;15:1065-75.

11. Tonini G, Imperatori M, Vincenzi B, Frezza AM, Santini D. Rechallenge therapy and treatment holiday: different strategies in management of metastatic colorectal cancer. J Exp Clin Cancer Res 2013;18:32:92. 
12. Maindrault-Goebel F, Tournigand C, André T, et al. Oxaliplatin reintroduction in patients previously treated with leucovorin, fluorouracil and oxaliplatin for metastatic colorectal cancer. Ann Oncol 2004;15:1210-4.

13. Suenaga M, Mizunuma N, Matsusaka S. A phase II study of oxaliplatin reintroduction in patients pretreated with oxaliplatin and Irinotecan for advanced colorectal cancer (RE-OPEN study): reports of interim analysis [abstract]. J Clin Oncol 2012;30:580.

14. Kang BW, Kim TW, Lee JL, et al. Bevacizumab plus FOLFIRI or FOLFOX as third-line or later treatment in patients with metastatic colorectal cancer after failure of 5-fluorouracil, irinotecan, and oxaliplatin: a retrospective analysis. Med Oncol 2009;26:32-7.

15. Ishiguro M, Watanabe T, Yamaguchi K, et al. A Japanese postmarketing surveillance of cetuximab $(\operatorname{Erbitux}(\mathrm{R}))$ in patients with metastatic colorectal cancer. Jpn J Clin Oncol 2012;42:287-94.

16. Jensen BV, Schou JV, Johannesen HH. Cetuximab every second week with irinotecan in patients with metastatic colorectal cancer refractory to 5-FU, oxaliplatin, and irinotecan: KRAS mutation status and efficacy. ASCO Meet Abstr 2010;28:3573.

17. Pfeiffer P, Nielsen D, Yilmaz M, Iversen A, Vejlø C, Jensen BV. Cetuximab and irinotecan as third line therapy in patients with advanced colorectal cancer after failure of irinotecan, oxaliplatin and 5-fluorouracil. Acta Oncol 2007;46:697-701.

18. Pfeiffer P, Nielsen D, Bjerregaard J, Qvortrup C, Yilmaz M, Jensen B. Biweekly cetuximab and irinotecan as third-line therapy in patients with advanced colorectal cancer after failure to irinotecan, oxaliplatin and 5-fluorouracil. Ann Oncol 2008;19:1141-5.
19. Sogabe S, Komatsu Y, Yuki S, et al. Retrospective cohort study on the safety and efficacy of bevacizumab with chemotherapy for metastatic colorectal cancer patients: the HGCSG0801 study. Jpn J Clin Oncol 2011;41:490-7.

20. Geva R, Vecchione L, Tejpar S, Piessevaux H, Van Cutsem E, Prenen H. Bevacizumab plus chemotherapy as salvage treatment in chemorefractory patients with metastatic colorectal cancer. Onco Targets Ther 2013;6:53-8.

21. Sonoda H, Mekata E, Shimizu T, Endo Y, Tani T. Safety and efficacy of panitumumab therapy after metastatic colorectal cancer progression with cetuximab: experience at a single Japanese institution. Oncol Lett 2013;5:1331-4.

22. Michalaki V, Gennatas S, Gennatas C. Mitomycin C and UFT/ leucovorin as salvage treatment in patients with advanced colorectal cancer. J BUON 2010;15:270-3.

23. Lee S, Kwon H-C, Kim S-H. Capecitabine monotherapy and the clinical significance of neutrophil-lymphocyte ratio versus platelet-lymphocyte ratio in patients with metastatic colorectal cancer. ASCO Meet Abstr 2012;30:660.

Corresponding Author: Ersin Özaslan, Department of Medical Oncology, Erciyes University Faculty of Medicine, 38039, Talas, Kayseri, Turkey

E-mail: dr-ozaslan@hotmail.com 